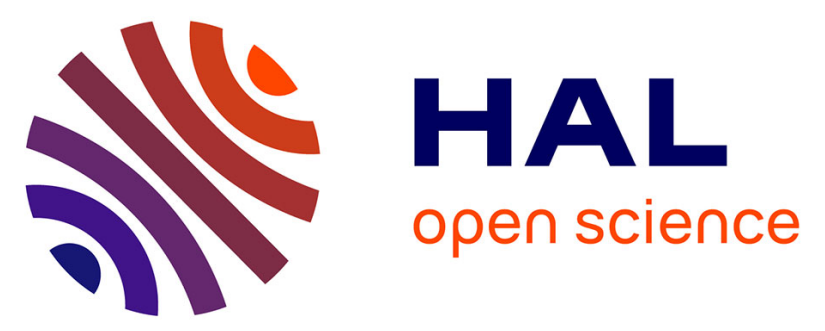

\title{
DISTAL MUSCLE INVOLVEMENT IN GRANULOMATOUS MYOSITIS CAN MIMIC INCLUSION BODY MYOSITIS
}

Sandrine Larue, Thierry Maisonobe, Olivier Benveniste, Catherine Chapelon-Abric, Olivier Lidove, Thomas Papo, Bruno Eymard, Odile Dubourg

\section{To cite this version:}

Sandrine Larue, Thierry Maisonobe, Olivier Benveniste, Catherine Chapelon-Abric, Olivier Lidove, et al.. DISTAL MUSCLE INVOLVEMENT IN GRANULOMATOUS MYOSITIS CAN MIMIC INCLUSION BODY MYOSITIS. Journal of Neurology, Neurosurgery and Psychiatry, 2010, 82 (6), pp.674. 10.1136/jnnp.2009.190751 . hal-00591161

\section{HAL Id: hal-00591161 https://hal.science/hal-00591161}

Submitted on 7 May 2011

HAL is a multi-disciplinary open access archive for the deposit and dissemination of scientific research documents, whether they are published or not. The documents may come from teaching and research institutions in France or abroad, or from public or private research centers.
L'archive ouverte pluridisciplinaire HAL, est destinée au dépôt et à la diffusion de documents scientifiques de niveau recherche, publiés ou non, émanant des établissements d'enseignement et de recherche français ou étrangers, des laboratoires publics ou privés. 


\section{DISTAL MUSCLE INVOLVEMENT IN GRANULOMATOUS MYOSITIS CAN MIMIC INCLUSION BODY MYOSITIS}

Sandrine Larue ${ }^{1}$, Thierry Maisonobe ${ }^{2,3}$, Olivier Benveniste ${ }^{1,4}$, Catherine Chapelon-Abric, ${ }^{5}$ Olivier Lidove, ${ }^{6}$ Thomas Papo, ${ }^{6}$ Bruno Eymard ${ }^{1}$, Odile Dubourg ${ }^{1,2}$

${ }^{1}$ Centre de Référence des Maladies Neuromusculaires "Paris-Est", APHP, CHU PitiéSalpêtrière, 47 Bd de l'hôpital, 75651 Paris Cedex 13, France

${ }^{2}$ Laboratoire de Neuropathologie, CHU Pitié-Salpêtrière, 47 Bd de l'hôpital, 75013 Paris, France

${ }^{3}$ Fédération de Neurophysiologie clinique, CHU Pitié-Salpêtrière, 47 Bd de l'hôpital, 75651 Paris Cedex 13, France

${ }^{4}$ Service de Médecine Interne 1, CHU Pitié-Salpêtrière, 47 Bd de l'hôpital, 75651 Paris Cedex 13, France

${ }^{5}$ Service de Médecine Interne 2, CHU Pitié-Salpêtrière, 47 Bd de l'hôpital, 75651 Paris Cedex 13, France

${ }^{6}$ Service de Médecine Interne, Groupe Hospitalier Bichat-Claude-Bernard, 46, rue HenriHuchard, 75877 Paris Cedex 18, France

Address correspondence to Dr O. Dubourg. Laboratoire de neuropathologie, Hôpital PitiéSalpêtrière, 47 Bd de l'hôpital, 75651 Paris Cedex 13. Tel: 33 (1) 421618 84, Fax: 33 (1) 42 1618 99, e-mail address: odile.dubourg@gmail.com

Keywords: inflammatory myopathy; inclusion body myositis; granulomatous myositis; sarcoidosis

Word count: 1646 


\title{
DISTAL MUSCLE INVOLVEMENT IN GM CAN MIMIC INCLUSION BODY MYOSITIS
}

\begin{abstract}
We report on four aged patients with chronic myopathy suggestive of sporadic inclusion body myositis. They presented progressive and selective weakness of the quadriceps femoris muscles. Asymmetric and selective atrophy of the forearm muscles was noted in all, with more severe involvement of the flexors than the extensors. Biopsy revealed granulomatous myositis. Histological features of s-IBM were lacking. Evidence for systemic sarcoidosis was found in one patient. Corticosteroid treatment was associated with partial but significant improvement in two patients. Granulomatous myositis may mimic inclusion body myositis and may be steroid-responsive.
\end{abstract}




\section{Introduction}

Sporadic IBM (s-IBM) is the most common acquired myopathy in patients over the age of 50, and involvement of the quadriceps and deep finger flexors are clues to its early diagnosis.[1] In contrast, granulomatous myositis (GM) is rare and found only in $0.4 \%$ of all muscle biopsy specimens.[2] We report on four aged patients with chronic myopathy suggestive of s-IBM, in whom muscle biopsy showed GM. Our four patients presented with progressive and relatively selective weakness of the quadriceps femoris muscles. Asymmetric and selective atrophy of the forearm muscles was also noted in all these patients, with more severe involvement of the flexors than the extensors. A diagnosis of s-IBM was made prior to muscle biopsy. Surprisingly, granulomas were found in muscle biopsy specimens obtained from these four patients, whereas no classical features of s-IBM could be identified. 


\section{Patients and Methods}

Patients. The patients were three women and one man, aged between 76 and 84 at the time of muscle biopsy. None of them had a past history of sarcoidosis. Muscle biopsy was performed on extensor carpi radialis in all patients. This muscle is easily accessible and often informative, in our experience, for a diagnosis of s-IBM, which was first suspected.

Muscle Pathology. Muscle samples were conventionally processed for light microscopy using standard procedures.[3] Frozen sections were stained with hematoxylin-eosin (H\&E), modified Gomori trichrome, Oil-red-O, periodic acid-Schiff (PAS), Congo Red and histoenzymatic reactions including NADH-tetrazolium reductase, succinate dehydrogenase, cytochrome C oxidase were performed. Several muscle fragments were paraffin-embedded and sections were stained with H\&E.

Expression of major histocompatibility complex (MHC)-1 (Dakocytomation, Glostrup, Denmark), CD3, CD4, CD8, CD20, CD68 (Dakocytomation, Glostrup, Denmark), and SMI31 (SMI-31R, Covance) were evaluated by immunoperoxidase assay performed on frozen sections, using an automated immunostainer (Ventana ${ }^{\circledR}$, Tucson, Az). Sporadic IBM was excluded in all patients by the absence of rimmed vacuoles in muscle fibers, the absence of amyloid deposits on Congo Red staining viewed under a Rhodamine red filter, and the absence of tubulo-filamentous inclusions with SMI-31 immunohistochemistry.[4] Biopsy findings for all patients are described in the table and illustrated in the figure. 


\section{Case Reports}

Patient 1: A 77-year-old woman presented with a six-year history of progressive difficulty in climbing stairs and steppage of the left foot. On examination, she had marked atrophy of both quadriceps and weakness of the left ankle dorsiflexor. Asymmetric and selective atrophy of her forearm flexor muscles was also noted. She had no dysphagia, myalgia, or skin rash. There was no family history of neurological disease and no relevant prior disease. A full workup, including complete blood cell count, erythrocyte sedimentation rate, antinuclear antibodies, biochemistry profile, immunoelectrophoresis, B12 vitamin, folate, angiotensinconverting enzyme, and thyroid-stimulating hormone was carried out to exclude possible associated systemic disorders, and was completely normal. The serum creatine kinase (CK) level was also normal. Electromyographic studies (EMG) revealed asymptomatic sensory neuropathy, and upon needle detection, myogenic motor unit potentials (MUPs) in affected muscles. Muscle biopsy revealed numerous giganto-epithelioid noncaseating granulomas invading the endomysial tissue. Muscle tissue was variably affected, either normal in some areas or very remodeled in others by a fibro-adipose involution containing atrophic and necrotic fibers and granulomatous lesions. Pulmonary sarcoid disease was suspected on chest computerized tomography (CT), since hilar adenopathies were identified. Bronchial biopsy confirmed the presence of granulomas. After starting prednisone therapy $(1 \mathrm{mg} / \mathrm{kg} / \mathrm{day})$, muscular strength in the proximal lower limbs progressively improved during the first four months, after which her clinical condition stabilized. One year later, while prednisone had been progressively reduced to $10 \mathrm{mg} / \mathrm{day}$, weakness reoccurred. The prednisone dose was then increased to the previous level and methotrexate introduced, which restored the patient's clinical status to what it was prior to prednisone reduction. 
Patient 2: An 84-year-old woman with a two-year history of progressive atrophy of both quadriceps and the left deep finger flexors. The blood workup was normal, except for a slightly elevated CK level (twofold the normal value.) There was no family history of neurological disease or relevant prior disease. Nerve conduction study revealed discrete sensory neuropathy and needle examination demonstrated myogenic MUPs in the atrophied muscles. Muscle biopsy showed signs of GM with variation in fiber size, necrosis and regeneration, diffuse inflammatory cells infiltrate invading non-necrotic fibers, and typical giganto-epithelioid granulomas. However, a sarcoidosis work-up was not carried out, since the patient refused further clinical investigation and declined follow-up.

Patient 3: An 81-year-old man who complained of frequent falls since age 74 related to weakness of his right anterior tibial muscle. At age 77, he presented with weakness and atrophy of both quadriceps muscles and the left forearm flexor muscles. Nerve conduction study demonstrated asymptomatic sensory neuropathy, and needle examination revealed myogenic MUPs in the atrophied muscles. Muscle biopsy revealed multiple and voluminous granulomatous lesions invading the endomysial connective tissue. The complete blood workup was normal, as were the chest CT, pulmonary function tests, and cerebral and lumbar magnetic resonance imaging (MRI).The patient was treated with corticosteroids $(1 \mathrm{mg} / \mathrm{kg} /$ day), with significant muscular strength improvement during the first six months of treatment, at the end of which he presented with acute hyponatremia related to a strict low sodium diet and diuretic treatment for hypertension, leading to severe weakness of all four limbs. Three months after adding methotrexate to the corticosteroids, the patient recovered the strength he had prior to electrolyte disequilibrium. His clinical condition has since remained stable. 
Patient 4: Over the past ten months, a 76-year-old woman presented progressive atrophy and weakness of both quadriceps muscles, anterior tibial muscles, and forearm flexors, suggestive of s-IBM. The complete blood workup was normal except for a moderate elevation of CK (1.3 the normal value.) The EMG demonstrated myogenic MUPs in the atrophied muscles. However, review of the patient's medical records revealed that she presented bladder polyps eight years before, for which she had been treated with Bacillus Calmette Guérin (BCG) therapy for two years. While under treatment, bilateral uveitis developed, for which antituberculosis therapy was administered during one year, with no efficacy. A sarcoidosis workup was then carried out and uveitis remained isolated. Interferon alpha-2A treatment was then tried and effective against the uveitis. However, two months after the start of interferon therapy, the patient developed myalgia and muscular weakness, as mentioned above. Muscle biopsy was performed 12 months after interferon introduction, revealing muscle fiber necrosis, inflammation, and giganto-epithelioid granulomas. This led to the assumption that interferon treatment had caused the GM.[5] Indeed, shortly after interferon was withdrawn, the myalgia disappeared and muscular strength slowly improved. Corticosteroids were not applied. 


\section{Discussion}

As opposed to other inflammatory myopathies in which weakness is mostly proximal, in sIBM, distal muscles are involved.[6] Early in the course of the disease, weakness and atrophy is typically observed in the quadriceps femoris and forearm flexors, often asymmetric. Sporadic IBM is not only the most frequent inflammatory myopathy encountered in patients aged 50 and over, but also the most likely diagnosis when a patient over 50 complains of falls and has atrophic thighs.[1] GM is clearly not as frequent and usually present with bilateral and symmetrical weakness of proximal lower limbs.[7] Distal involvement may be observed as the disease develops, but is rarely present at the outset. [7] It is therefore not surprising that our patients were first diagnosed with s-IBM.

Histological diagnosis of s-IBM is challenging, since the distribution of muscle abnormalities is patchy and the complete biopsy criteria may be missing even from clinically affected muscles.[8] Similarly, granuloma in muscle may be easily overlooked unless numerous paraffin sections are examined. Thorough histological investigation of frozen and paraffin sections of several muscle fragments are therefore essential for diagnosis in both situations. Few cases of association between sarcoidosis or other autoimmune disorders and s-IBM have been described.[9-12] In our muscle biopsy specimen, we did not detect amyloid or tubulofilamentous inclusions, which are markers of degenerative changes in s-IBM,[4] leading us to conclude that our patients just had GM.

The classically held view of s-IBM is that it clinically differs from other types of inflammatory myopathies by its male preponderance, muscle weakness, atrophy topography, and protracted course. Resistance to treatment with conventional forms of immunotherapy is 
also a feature of s-IBM.[1] On the other hand, GM may be significantly improved by steroids, although such response is unpredictable. Discrepancies among various studies may be due to the different proportions of acute and chronic myositis cases included, since the former has a better response to steroids and a more benign course.[7] In our patients 1 and 3, who suffered from chronic myopathy, steroids were efficient.

The prevalence of granulomas in muscle biopsies is low, and sarcoidosis is known to be the single most commonly identifiable cause.[2] The prevalence of asymptomatic GM in sarcoidosis has been reported to be as high as 50-80\%.[13] Symptomatic involvement is clearly less common, and includes various types: nodular, acute myositis, or the more common, chronic myopathy, as in patient 1 , which is slower in onset and occurs later in life.[7] GM may also occur without systemic involvement. Although muscle pathology is similar to that seen in sarcoidosis, isolated GM is usually considered a separate clinicopathological entity. However, in most series and case reports, it remains unclear whether GM simply reflects an incomplete sarcoidosis work-up.[7]

It is possible to speculate why some patients with GM present with a similar clinical pattern to s-IBM. It could be related to the level of expression of IL-1beta, which is high in sarcoid myopathy granuloma and s-IBM.[14,15] In spite of the age of the patients with GM in this report, the mechanism of ageing could also contribute to the unique pattern of affected muscles in both diseases.

Regardless whether granulomatosis is systemic or limited to muscles, it can occur late in life and manifests as a chronic myopathy strongly suggestive of s-IBM. Corticosteroids should be 
tried whenever GM is symptomatic. Although it is rare, recognizing GM remains important from both the prognostic and therapeutic points of view.

Licence for Publication: The Corresponding Author has the right to grant on behalf of all authors and does grant on behalf of all authors, an exclusive licence (or non exclusive for government employees) on a worldwide basis to the BMJ Publishing Group Ltd to permit this article (if accepted) to be published in JNNP and any other BMJPGL products and sublicences such use and exploit all subsidiary rights, as set out in our licence.

Competing Interest: None declared.

Acknowledgements: This work was supported by the Association Française contre les Myopathies (AFM), by the Assistance Publique des Hôpitaux de Paris (APHP), and the Université Pierre et Marie Curie. 
Table 2: Muscle pathology

\begin{tabular}{|c|c|c|c|c|}
\hline & Case 1 & Case 2 & Case 3 & Case 4 \\
\hline $\begin{array}{l}\text { Time from disease onset to biopsy } \\
\text { (years) }\end{array}$ & 6 & 2 & 7 & 1 \\
\hline \multicolumn{5}{|l|}{ Pathological features } \\
\hline Variation of fiber caliber & + & + & + & + \\
\hline Muscle fiber pathology & & & & \\
\hline Necrosis & + & + & + & + \\
\hline Ragged red fibers & + & + & + & + \\
\hline Rimmed vacuoles & - & - & - & \\
\hline $\begin{array}{l}\text { Percentage of COX-negative } \\
\text { fibers }\end{array}$ & $2 \%$ & $4 \%$ & $1 \%$ & $10 \%$ \\
\hline Congo-Red deposits & - & - & - & - \\
\hline $\begin{array}{l}\text { Invasion of non-necrotic fibers by } \\
\text { CD8-positive T cells }\end{array}$ & + & - & + & + \\
\hline Giganto-epithelioid granulomas & + & + & + & + \\
\hline $\begin{array}{l}\text { Immunohistochemistry } \\
\text { Diffuse (MHC)-1 } \\
\text { SMI-31 deposits }\end{array}$ & $\begin{array}{l}+ \\
-\end{array}$ & $\begin{array}{l}+ \\
-\end{array}$ & + & $\begin{array}{l}+ \\
-\end{array}$ \\
\hline
\end{tabular}




\section{Figure legend}

Cryostat sections stained with Gomori trichrome (A,D,H,J), immunostained with anti-(MHC)-

1 (B,E,K) and anti-CD8 lymphocytes antibodies (F,L). Gomori trichrome stain revealed normal tissue in (A), indicating that pathological findings may be very focal, endomysial inflammation and partial invasion of a fiber (arrow) in (B), diffuse granulomas in (C) and variation of fiber caliber and ragged-red-fibers (curved arrow) in (D). (MHC)-1 was diffusely overexpressed in all biopsies. Invasion of non-necrotic fibers by CD8 lymphocytes was occasionally observed (arrowhead). Paraffin sections stained with hematoxylin-eosin (C, G, I, M) revealed giganto-epithelioid granulomas. 


\section{References}

[1] Dalakas MC. Sporadic inclusion body myositis-diagnosis, pathogenesis and therapeutic strategies. Nat Clin Pract Neurol 2006;2:437-47.

[2] Prayson RA. Granulomatous myositis. Clinicopathologic study of 12 cases. Am J Clin Pathol 1999;112:63-8.

[3] Dubowitz V, Sewry C. Muscle biopsy: A practical approach. Third Edition. Saunders, Elsevier, 2007.

[4] Engel WK, Askanas V. Inclusion-body myositis: clinical, diagnostic, and pathologic aspects. Neurology 2006;24;66(2 Suppl 1):S20-S29.

[5] Leclerc S, Myers RP, Moussalli J, et al. Sarcoidosis and interferon therapy: report of five cases and review of the literature. Eur J Intern Med 2003;14:237-43.

[6] Briani C, Doria A, Sarzi-Puttini P, et al. Update on idiopathic inflammatory myopathies. Autoimmunity 2006;39:161-70.

[7] Le Roux K, Streichenberger N, Vial C, et al. Granulomatous myositis: a clinical study of thirteen cases. Muscle Nerve 2007;35:171-77.

[8] Chahin N, Engel AG. Correlation of muscle biopsy, clinical course, and outcome in PM and sporadic IBM. Neurology 2008;70:418-24.

[9] Bouillot S, Coquet M, Ferrer X, et al. [Inclusion body myositis associated with sarcoidosis: a report of 3 cases]. Ann Pathol 2001;21:334-6.

[10] Vattemi G, Tonin P, Marini M, et al. Sarcoidosis and inclusion body myositis. Rheumatology. 2008;47:1433-5.

[11] Danon MJ, Perurena OH, Ronan S, Manaligod JR. Inclusion body myositis associated with systemic sarcoidosis. Can J Neurol Sci 1986;13:334-6. 
[12] Badrising UA, Schreuder GM, Giphart MJ, et al. Associations with autoimmune disorders and HLA class I and II antigens in inclusion body myositis.Neurology 2004;63:2396-8.

[13] Silverstein A, Siltzbach LE. Muscle involvement in sarcoidosis. Asymptomatic, myositis, and myopathy. Arch Neurol 1969;21:235-41.

[14] Authier FJ, Mhiri C, Chazaud B, et al. Interleukin-1 expression in inflammatory myopathies: evidence of marked immunoreactivity in sarcoid granulomas and muscle fibres showing ischaemic and regenerative changes. Neuropathol Appl Neurobiol 1997;23:132-40.

[15] Schmidt J, Barthel K, Wrede A, Salajegheh M, Bähr M, Dalakas MC. Interrelation of inflammation and APP in sIBM: IL-1 beta induces accumulation of beta-amyloid in skeletal muscle. Brain 2008;131:1228-40. 

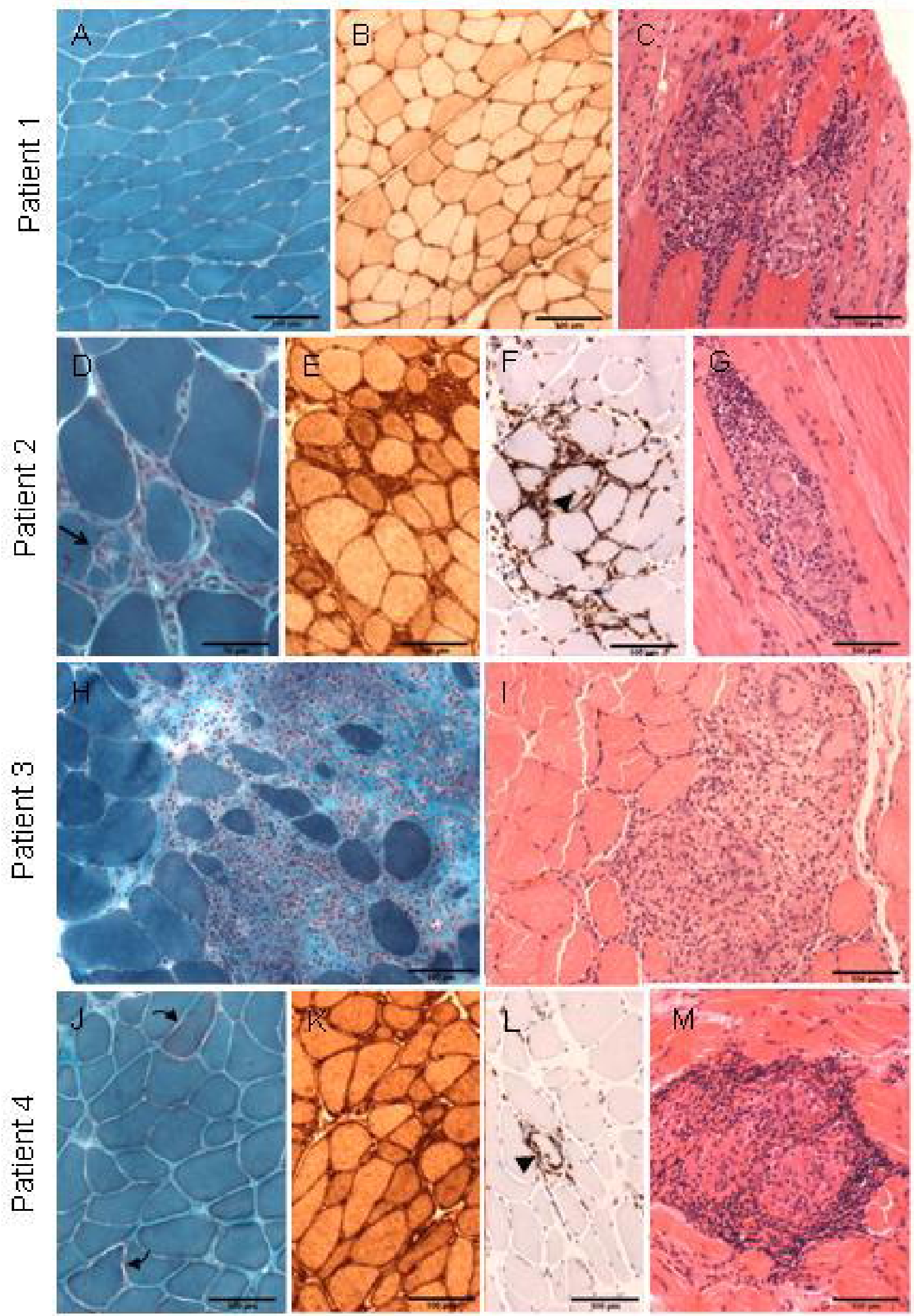